\title{
Exames soroepidemiológicos sobre a leucose enzoótica dos bovinos no Estado do Pará, Brasil
}

\section{A sero-epidemiological survey on the bovine enzootic leukosis in Pará State, Brazil}

\author{
Éva Molnár, ${ }^{\star}$ László Molnár, ${ }^{\star}$ Mara Carvalho, ${ }^{\star *}$ Emilia Socorro de Lima***
}

\begin{abstract}
Resumo
Foram realizados exames soroepidemiológicos em três rebanhos bovinos através das provas de ELISA indireto e imunodifusão em gel de ágar, utilizando-se o antígeno glicoprotéico (gp51) para examinar a proporção da infecção dos bezerros oriundos de vacas infectadas, o desaparecimento de anticorpos maternos e a possibilidade de erradicação da doença em condições extensivas. Utilizando a imunodifusão, os anticorpos maternos desapareceram até quatro a cinco meses de idade, e no ELISA foram encontrados bezerros soropositivos também com idade de seis meses. Nas condições desta região (desmame aos seis a oito meses de idade), a proporção de soropositividade de bezerros oriundos de mães soropositivas atingiu 20 a 33,3\% dos animais na faixa de 11 a 15 meses de idade. Assim, utilizando o ELISA, que é um teste mais sensível que a imunodifusão, parece ser possível monitorar a erradicação desta enfermidade em tais condições.
\end{abstract}

Palavras-chave: leucose enzoótica dos bovinos; ELISA indireto; imunodifusão em gel deágar; erradicação; anticorpos maternos.

\section{Introdução}

O linfossarcoma dos bovinos pode ser dividido de quatro formas: bezerro (juvenil), tímica, cutânea e adulto multicêntrica. As formas bezerro, tímica e cutânea são conhecidas

como leucoses esporádicas dos bovinos, não existindo dados que comprovem que as mesmas sejam enfermidades infecciosas (Klintevall et al., 1993). Somente a forma adulta multicêntrica de linfossarcoma pode ser produzida pelo Vírus da Leucose dos Bovinos (VLB; Van der Maaten \& Miller, 1990), sendo essa enfermidade denominada de Leucose Enzoótica dos Bovinos (LEB).

A LEB está distribuída no mundo todo. O agente etiológico é um retrovírus que ocorre naturalmente nos bovinos, sendo sua presença também demonstrada em ovinos, bubalinos e capivaras (Burny et al., 1980 e 1985). Nos bovinos os tumores desenvolvem-se muito raramente: segundo Buehring et al. (1994), o VLB produz geralmente uma infecção subclínica, e menos que $1 \%$ dos animais infectados desenvolve linfoma de células após alguns anos de infecção. Outros pesquisadores pensam que a proporção de animais com linfossarcoma é mais alta (Burny et al., 1980 e 1985).
Em todas as espécies de animais sensíveis, a infecção com VLB induz anticorpos contra proteínas do vírus. Os anticorpos induzidos pela glicoproteína do envelope (gp 51) aparecem mais rapidamente (dentro de duas semanas após a infecção), alcançando um título muito alto que persiste durante a vida do animal infectado (Bex et al., 1979). Estes anticorpos influenciam na difusão do vírus, de certa forma (Mészáros et al., 1986).

Embora a infecção germinativa não ocorra, a transmissão transplacentária pode ocorrer. Segundo Mészáros et al. (1986), isso só acontece excepcionalmente; outros estimam que esse tipo de infecção ocorra entre 13 e $18 \%$ dos bezerros nascidos de vacas infectadas (Ferrer et al., 1976; Piper et al., 1979). A situação, quanto à infecção através do colostro ou leite, é muito semelhante: segundo Birgel Júnior et al. (1995), isso é pouco freqüente; para Mészáros et al. (1986), essa proporção pode ultrapassar os $10 \%$.

Após a descoberta de que a LEB é causada por um vírus (Miller, 1969), vários métodos foram elaborados para a demonstração da infecção. Para este fim, têm sido utilizados, principalmente, os testes sorológicos, entre eles a imunofluorescência indireta, imunodifusão em gel de ágar (IDAG), fixação do complemento, radioimunoensaio, vírusneutralização e ELISA. Várias pesquisas comparativas

\footnotetext{
* Pesquisadores Visitantes do CNPq, Centro Agropecuário, Universidade Federal do Pará, UFPA, Campus Universitário do Guama, 66075-900 Belém, Pará, Brasil.

** Médica Veterinária, bolsista de Aperfeiçoamento do CNPq.

${ }^{\star \star *}$ Acadêmica em Medicina Veterinária, bolsista de Iniciação Científica do CNPq.
} 
foram feitas a respeito da sensibilidade e aplicabilidade desses diferentes métodos (Miller et al., 1981; Manz et al., 1981; Cokerell and Rovnak, 1988). Em geral, é possível verificar que nos últimos 15 anos a IDAG e o ELISA têm sido usados mais amplamente para detectar a infecção por VLB no mundo todo (Tekes, 1994).

Em um exame realizado anteriormente, avaliou-se a situação quanto à ocorrência da LEB no Estado do Pará e constatou-se que o ELISA foi muito mais sensivel que a prova de IDAG. Então, os objetivos do presente trabalho foram fornecer informações adicionais sobre a sensibilidade destas duas provas e avaliar alguns detalhes da epidemiologia da LEB, em condições extensivas na região tropical úmida.

\section{Material e Métodos}

Foram avaliadas amostras de sangue de dois rebanhos:

- Rebanho1. Rebanho leiteiro, altamente infectado por VLB. Os bezerros de 10 vacas positivas pelo ELISA e IDAG foram examinados quatro vezes durante 20 meses em ambas as provas.

- Rebanho 2. O rebanho Nelore contou com 166 vacas e seus descendentes. Após o primeiro exame, as vacas foram divididas em dois grupos: positivas e negativas; entretanto, ambos os grupos foram examinados outras duas vezes por ambas as provas. De 29 vacas positivas no ELISA e negativas na IDAG no primeiro exame, 14 permaneceram no rebanho durante um a três meses antes do parto, e as mesmas foram testadas durante sete meses, mensalmente. Também foram examinados soros de 44 animais ( 25 provindos de vacas positivas e 19 de vacas não-infectadas) quatro vezes até chegarem à idade de 15 meses.

Todas as amostras de soros foram examinadas por ELISA indireto e IDAG. Para o diagnóstico através do método de ELISA, foi utilizado Leukosis ELISA kit, fornecido pela
Animal Production Unit, Joint FAO/IAEA Agriculture and Biotechnology Laboratory, Agency Laboratóries Division, Seiberdorf, Austria, que apresenta as seguintes características: o antígeno empregado consiste na glicoproteína (gp 51) do BLV, derivado de cultura de células. Utilizou-se um conjugado comercial constituído por IgG monoclonal de camundongo anti-bovina, conjugada com peroxidase de raiz-forte (horseradish peroxidase, HRPO, Sigma). Foram usados como controle soros forte e fracamente positivos e negativos, oriundos de bovinos. Os soros para teste foram diluídos a 1:50 e examinados em duplicata. Procedia-se à repetição dos exames nos casos em que os valores individuais estivessem fora do valor de PP (por cento de positividade), estabelecido como padrão. A leitura da densidade ótica foi realizada no aparelho de "Immunoscan BDSL" com medição do desenvolvimento de cor de substrato a $450 \mathrm{~nm}$. O software utilizado foi o EDI com o valor 35 de cut-off.

A imunodifusão foi realizada segundo Tekes et al. (1984), usando-se antígeno glicoprotéico (gp51) produzido pelo laboratório BIOVETA. ${ }^{1}$ Com esta metodologia, foram analisadas as amostras de soros, utilizando-se placas de Petri de $9 \mathrm{~cm}$ de diâmetro.

\section{Resultados}

Examinando o soro dos animais do Rebanho 1, verificouse que os bezerros entre dois e três meses de idade apresentaram $100 \%$ de anticorpos anti-VLB no ELISA e $60 \%$ pela IDAG (Tabela 1). A proporção de soropositividade diminuiu para 40 e $10 \%$, nas respectivas provas, até a idade de 4 a 5 meses. Dos 10 aos 11 meses de idade foram encontrados dois animais soropositivos no ELISA e nenhum na IDAG, e nove meses mais tarde esta proporção aumentou para três e dois animais positivos, nas respectivas provas.

Tabela 1: Resultados sorológicos dos animais oriundos de vacas soropositivas do Rebanho 1

\begin{tabular}{|c|c|c|c|c|c|c|c|c|}
\hline \multirow{3}{*}{$\begin{array}{l}\mathrm{n}^{\circ} \text { de } \\
\text { ordem }\end{array}$} & \multicolumn{8}{|c|}{ (meses) } \\
\hline & \multicolumn{2}{|c|}{2 a 3} & \multicolumn{2}{|c|}{4 a 5} & \multicolumn{2}{|c|}{10 a 11} & \multicolumn{2}{|c|}{19 a 20} \\
\hline & ELISA & IDAG & ELISA & IDAG & ELISA & IDAG & ELISA & IDAG \\
\hline 1. & + & - & + & - & - & - & - & - \\
\hline 2. & + & + & + & - & - & - & - & - \\
\hline 3. & + & + & + & + & + & - & + & + \\
\hline 4. & + & + & - & - & - & - & - & - \\
\hline 5. & + & - & - & - & - & - & - & - \\
\hline 6. & + & + & - & - & + & - & + & + \\
\hline 7. & + & + & + & - & - & - & + & - \\
\hline 8. & + & - & - & - & - & - & - & - \\
\hline 9. & + & - & - & - & - & - & - & - \\
\hline 10. & + & + & - & - & - & - & - & - \\
\hline Total & 10 & 6 & 4 & 1 & 2 & 0 & 3 & 2 \\
\hline
\end{tabular}

1 BIOVETA Komenského 212, 68323 Ivanovice na Hané, República Tcheca. 
No Rebanho 2, no primeiro exame, $60,8 \%$ das vacas mostraram-se positivas (101/166) no ELISA, e 43,2\% (72/166) na IDAG. Vinte e nove animais apresentaram-se positivos somente pelo ELISA, e dentro do grupo $(n=166)$ nenhum animal manifestouse positivo somente na IDAG (Tabela 2). No segundo teste, realizado seis meses após o primeiro, todas as vacas positivas no ELISA afirmaram-se novamente positivas, e somente uma negativa tornou-se positiva. Outrossim, elevou-se o número de animais sororreagentes na IDAG. No terceiro exame não se encontrou mais sororreagente no grupo negativo em ambas as provas; entretanto, aumentou-se consideravelmente o número de sororreagentes na IDAG (Tabela 2).

Os resultados dos exames realizados com as amostras de 14 vacas que estavam no último estágio de prenhez, por ocasião do primeiro teste, são demonstrados na Tabela 3. Um animal ( $\left.n^{\circ} 1\right)$ apresentou sorologia falso-negativa na IDAG três meses antes do parto, sendo que o mesmo tornou-se fracamente positivo um mês mais tarde $e$ por ocasião do terceiro exame mostrou-se outra vez negativo. Quatro vacas ( $\mathrm{n}^{\mathrm{os}} 2,3,4$ e 5 ) foram falsonegativas na IDAG dois meses antes do parto, e nove vacas ( $n^{\text {es }} 6$ a 14) foram falso-negativas nesta prova um mês antes do parto. No dia do parto, todas as vacas foram positivas no ELISA e negativas na IDAG. Um mês após o parto, cinco animais ( $n^{\circ s} 1,2,4,7$ e 8 ) continuaram negativos. O ELISA demonstrou positividade em todos os casos, exceto o animal $n^{\circ}$ 12 , que se apresentou falso-negativo em ambas as provas, três meses após o parto.

Tabela 2: Exames sorológicos das vacas do Rebanho 2

\begin{tabular}{ccccccc}
\hline Data do exame & $\begin{array}{c}\text { Número de } \\
\text { animais } \\
\text { examinados }\end{array}$ & $\begin{array}{c}\text { Número de animais } \\
\text { negativos em ambas as } \\
\text { provas }\end{array}$ & \multicolumn{3}{c}{ Número de animais positivos } \\
\cline { 3 - 6 } & & $\begin{array}{c}\text { Somente } \\
\text { ELISA }\end{array}$ & $\begin{array}{c}\text { Somente } \\
\text { IDAG }\end{array}$ & $\begin{array}{c}\text { ELISA } \\
\text { total }\end{array}$ & $\begin{array}{c}\text { IDAG } \\
\text { total }\end{array}$ \\
\hline $05 / 03 / 97$ & 166 & 65 & 29 & 0 & 101 & 72 \\
$10 / 09 / 97$ & 166 & 64 & 21 & 0 & 102 & 81 \\
$03 / 02 / 98$ & 165 & 64 & 12 & 0 & 101 & 89 \\
\hline
\end{tabular}

Tabela 3: Resultados sorológicos de vacas do Rebanho 2 positivas pelo ELISA e negativas pela IDAG

\begin{tabular}{|c|c|c|c|c|c|c|c|c|c|}
\hline \multirow[t]{2}{*}{ № de animal } & \multirow[t]{2}{*}{ Prova } & \multicolumn{3}{|c|}{ Antes do parto } & \multirow[t]{2}{*}{ Parto } & \multicolumn{4}{|c|}{ Após o parto } \\
\hline & & $3^{0}$ mês & $2^{0}$ mês & $1^{0}$ mês & & $1^{\circ}$ mês & $2^{\circ}$ mês & $3^{\circ}$ mês & $4^{-}$mês \\
\hline \multirow[t]{2}{*}{1} & ELISA & + & + & + & + & + & + & + & $0^{\star}$ \\
\hline & IDAG & - & + & - & - & - & + & + & 0 \\
\hline \multirow[t]{2}{*}{2} & ELISA & 0 & + & + & + & + & + & + & + \\
\hline & IDAG & 0 & . & - & - & - & + & + & + \\
\hline \multirow[t]{2}{*}{3} & ELISA & 0 & + & + & + & + & 0 & + & + \\
\hline & IDAG & 0 & - & - & - & + & 0 & + & + \\
\hline \multirow[t]{2}{*}{4} & ELISA & 0 & + & + & + & + & 0 & + & + \\
\hline & IDAG & 0 & - & - & - & - & 0 & + & + \\
\hline \multirow[t]{2}{*}{5} & ELISA & 0 & + & + & + & + & + & + & + \\
\hline & IDAG & 0 & - & - & - & + & + & + & + \\
\hline \multirow[t]{2}{*}{6} & ELISA & 0 & + & + & + & + & + & + & + \\
\hline & IDAG & 0 & + & - & - & + & + & + & + \\
\hline \multirow[t]{2}{*}{7} & ELISA & 0 & 0 & + & + & + & + & 0 & + \\
\hline & IDAG & 0 & 0 & - & - & - & + & 0 & + \\
\hline \multirow[t]{2}{*}{8} & ELISA & 0 & 0 & + & + & + & 0 & + & + \\
\hline & IDAG & 0 & 0 & - & - & - & 0 & + & + \\
\hline \multirow[t]{2}{*}{9} & ELISA & 0 & 0 & + & + & + & + & + & + \\
\hline & IDAG & 0 & 0 & - & - & + & + & + & + \\
\hline \multirow[t]{2}{*}{10} & ELISA & 0 & 0 & + & + & + & + & + & + \\
\hline & IDAG & 0 & 0 & - & - & + & + & + & + \\
\hline \multirow[t]{2}{*}{11} & ELISA & 0 & 0 & + & + & + & 0 & + & + \\
\hline & IDAG & 0 & 0 & - & - & + & 0 & + & + \\
\hline \multirow[t]{2}{*}{12} & ELISA & 0 & 0 & + & + & 0 & + & - & + \\
\hline & IDAG & 0 & 0 & : & - & 0 & - & - & + \\
\hline \multirow[t]{2}{*}{13} & ELISA & 0 & 0 & + & + & + & + & + & + \\
\hline & IDAG & 0 & 0 & - & - & + & + & + & + \\
\hline \multirow[t]{2}{*}{14} & ELISA & 0 & 0 & + & + & + & 0 & + & + \\
\hline & IDAG & 0 & 0 & & - & + & 0 & + & + \\
\hline
\end{tabular}

*O exame não foi feito. 
$\mathrm{Na}$ Tabela 4 são evidenciados os resultados efetuados com soro de bezerros de até 15 meses de idade. Entre dois e quatro meses de idade, $96 \%(24 / 25)$ e $32 \%(8 / 25)$ dos bezerros oriundos de vacas infectadas possuíam anticorpos em quantidade suficiente para serem positivos no ELISA e na IDAG, respectivamente. Dos 13 aos 15 meses de idade, $33,3 \%(8 / 24)$ dos animais descendentes de vacas sororreagentes foram positivos no ELISA, e um dos bezerros nascido de uma vaca soronegativa também tornou-se soropositivo aos 15 meses de idade.

Tabela 4: Resultados sorológicos dos bezerros do Rebanho 3que nasceram entre 11/10/96 e 31/12/96

\begin{tabular}{|c|c|c|c|c|c|c|c|}
\hline \multirow[t]{2}{*}{$\begin{array}{l}\text { Data do } \\
\text { exame }\end{array}$} & \multirow[t]{2}{*}{$\begin{array}{l}\text { Idade dos } \\
\text { bezerros }\end{array}$} & \multicolumn{3}{|c|}{$\begin{array}{c}\text { Nascidos de vacas infectadas } \\
\text { positivos }\end{array}$} & \multicolumn{3}{|c|}{$\begin{array}{c}\text { Nascidos de vacas soronegativas } \\
\text { positivos }\end{array}$} \\
\hline & & Examinados & ELISA & IDAG & Examinados & ELISA & IDAG \\
\hline $06 / 03 / 97$ & 2-4 meses & 25 & 24 & 8 & 19 & 0 & 0 \\
\hline $12 / 05 / 97$ & 5-6 meses & 25 & 8 & 1 & 19 & 0 & 0 \\
\hline $09 / 10 / 97$ & $10-12$ meses & 25 & 7 & 2 & 19 & 0 & 0 \\
\hline $23 / 01 / 98$ & $13-15$ meses & 24 & 8 & 4 & 19 & 1 & 0 \\
\hline
\end{tabular}

\section{Discussão}

Está bem estabelecido que o VLB pode ser transferido vertical e horizontalmente. Em termos teóricos, as vias verticais são: germinativa, intra-uterina, durante o parto e através da ingestão do colostro e/ou leite. A infecção germinativa não ocorre (Mészáros et al. 1986). Sobre a possibilidade da transmissão transplacentária, as opiniões são bastantes divergentes. Segundo Ferrer et al. (1976), Piper et al. (1979) e Birgel Júnior et al. (1995), este tipo de transmissão ocorre em cerca de 13 a $18 \%$ dos bezerros. Mészáros et al. (1986), examinando cerca de mil amostras de soro pré-colostral de bezerros oriundos de vacas sororreagentes na IDAG, não encontraram qualquer amostra positiva. Baseados nestes exames, os pesquisadores não excluíram a possibilidade da infecção intra-uterina; entretanto, pressupõem que esse tipo de transmissão raramente ocorra. Cordeiro et al. (1994), ao examinar seis animais, filhas de vacas soropositivas, durante um ano, confirmaram que todas foram negativas nos exames e concluíram que a possibilidade de transmissão intra-uterina ou durante a fase de aleitamento não existe ou ocorre só excepcionalmente.

A transmissão do VLB através da ingestão de leite foi reportada por vários pesquisadores (Romero et al., 1983; Modena et al., 1984; Mészáros et al., 1986); porém Cordeiro et al. (1994) discordam dessa possibilidade. Devido à possibilidade de transmissão colostral, Modena et al. (1984) recomendaram a nãoutilização de leite ou colostro de animais reagentes à IDAG. Oliveira et al. (1994) aconselharam evitar a ingestão de colostro de soropositivos pelos recém-nascidos nas primeiras 48 horas. Mészáros et al. (1986), porém, recomendam o oposto: os recém-nascidos podem receber colostro de mães soropositivas somente nas primeiras 72 horas. Segundo os autores, o colostro contém anticorpos contra o vírus nos primeiros três dias em altas concentrações, suficientes na maioria das vezes para neutralizar ovírus.
Conforme os resultados apresentados, foi demonstrado claramente que os bezerros podem infectar-se através de suas mães. No Rebanho 2, 33,3\% (8/24) dos bezerros nascidos de mães infectadas foram sororreagentes no ELISA dos 13 aos 15 meses de idade (Tabela 4). A proporção de soropositivos na IDAG foi justamente a metade.

Os exames realizados no Rebanho 1 demonstraram resultados muito semelhantes aos citados anteriormente. Embora seja impossível afirmar que a infecção de dois animais aos 10 meses de idade (nos 3 e 6 ) aconteceu através de suas mães, isso provavelmente pode ser considerado. No que se refere ao animal $n^{\circ} 7$, já é mais difícil declarar a possibilidade de infecção desta maneira.

Os exames realizados neste trabalho não são capazes de diferenciar a transmissão transplacentária daquela através do leite. Teoricamente, esta diferenciação tem grande importância; entretanto, na prática é quase indiferente se o bezerro infectou-se no útero ou alguns dias após o nascimento (exceto em alguns casos em que o bezerro nasce imunotolerante, fato este que ainda não está bem estudado no caso de LEB).

As vias de infecção horizontal são bem estudadas. Entretanto, vale ressaltar que, após a divisão dos animais em positivos e negativos, foi encontrado somente um caso positivo no segundo teste, embora a proporção de sororreagentes fosse muito alta $(60,8 \%)$ no primeiro exame (Tabela 2). Com certeza, esse último animal já estava infectado, somente não soroconvertido no momento do primeiro exame. Os bezerros foram desmamados aos seis meses de idade e agrupados juntamente com aqueles nascidos de vacas soropositivas e não infectados. Após nove meses de coabitação, somente um animal tornou-se soroconvertido dentre 19 animais. Estes dados demonstram que, embora a infecção horizontal possa ocorrer, várias vezes a via verdadeira é impossível de se determinar; entretanto, se o manejo e a tecnologia empregados são 
adequados, e não houver contaminação através do sangue (agulhas, materiais cirúrgicos, tatuagens etc.), o vírus propaga-se lentamente (por contato direto, artrópodes). Tekes (1989) demonstrou que a erradicação da LEB é possível, quando os animais infectados e não-infectados são colocados em um mesmo estábulo, sendo que os dois grupos devem ficar separados pelo menos dois a três metros de distância um do outro.

Nos últimos 15 anos, os testes de IDAG e ELISA são utilizados para o diagnóstico da LEB em massa. Sem dúvida, tais provas são muito úteis na avaliação epidemiológica e no combate contra esta doença. Os primeiros programas de erradicação foram baseados nos resultados da IDAG, e a mesma é aceita também, atualmente, para fins comerciais de exportação ou importação de animais. Entretanto, inúmeras pesquisas demonstram que o teste ELISA é mais sensível que a IDAG (Behrens et al., 1979; Manz et al., 1981; Bauer et al., 1984; Klintevall et al., 1993; Tekes et al., 1994; Islas et al., 1995). Em uma pesquisa, Tekes (1994) demonstrou que os animais estabulados podem dar resultado falso negativo em até $26 \%$. No mesmo trabalho pôde-se afirmar, também, que no momento do parto $25 \%$ das vacas infectadas tornaram-se negativas na IDAG. Diminuíram ainda os títulos séricos no ELISA; entretanto, esse decréscimo nunca foi tão grande que a prova se tornasse negativa em diluição de rotina (1:40). Com a sensibilidade do ELISA, pode-se explicar que os animais infectados tornam-se positivos no ELISA mais rapidamente (30 dias) que na IDAG (90 dias) (Islas et al., 1995). Nossos resultados estão de acordo com os citados. Ao examinar nesta pesquisa cerca de 800 amostras de soro, nunca existiram amostras positivas na IDAG e negativas na ELISA; entretanto, o inverso sempre ocorreu (ver tabelas).

Os exames sorológicos devem servir para monitorar a erradicação desta enfermidade. Baseados na literatura brasileira e em nossos exames realizados no Estado do Pará, atualmente, esta situação é crítica e se não for tomada alguma atitude para resolver tal problema, as condições tornar-se-ão mais agravantes, e talvez a erradicação da LEB seja irresoluta. Por outro lado, é preciso salientar que o ELISA pode auxiliar no monitoramento do processo de erradicação, e os rebanhos altamente infectados podem tornar-se livres do VLB em um curto espaço de tempo, como demonstrou o caso do Rebanho 2. Ainda assim, o leite das vacas infectadas tem grande importância na divulgação da infecção (33,3\% dos bezerros nascidos de vacas soropositivas foram infectados dos 13 aos 15 meses de idade), e o desmame precoce ou a alimentação artificial poderiam dar bons resultados.

Sumarizando as mais importantes observações deste trabalho, é importante salientar:

- A IDAG é uma prova excelente, barata, prática e específica para uma avaliação epidemiológica. Ao se usar esta prova, é importante destacar que a mesma não é suficientemente sensível, em primeiro lugar no momento do. parto e um a dois meses antes e após o parto, fortalecendo os dados já conhecidos (Bause et al., 1978; Bause e Schmidt, 1980; Burridge et al., 1982).

- O ELISA é mais sensível, e até agora não foi demonstrado que ele produz reações falso-positivas. Nesses exames, a grande maioria dos animais positivos no ELISA e negativos na IDAG tornou-se positiva também neste último dentro de um a dois meses.

A esta maior sensibilidade do ELISA pode ser atribuído 0 fato de que, no segundo exame do Rebanho 2, houve uma só vaca positiva (Tabela 2). Utilizando a prova da IDAG para erradicação, foram necessários de 3 a 10 exames (Cordeiro et al., 1994; Mészáros et al., 1986).

Os bezerros nascidos de vacas infectadas podem adquirir o VLB. Assim, ao utilizar o ELISA, aconselha-se começar os exames destes animais entre os sete e oito meses de idade.

\begin{abstract}
A seroepidemiological survey was made in three bovine herds with indirect ELISA and agar-gel immunodiffusion test using glycoprotein antigen (gp51) for determine the infection rate of calves originated of infectious cows, disappearence of maternal antibodies and the possibilities of the eradication of the disease in extensive conditions. Using the immunodiffusion test the maternal antibodies disappeared until 4 or 5 months of age but in ELISA could be demonstrated seropositivity with 6 month of age in some calves. Under the conditions existing in this region (weaning at 6 or 8 months of age), the rate of seropositivity in the growing stock originated of infected cows reaches 20 or $33,3 \%$ of animals till 11 or 15 months of age. It seems that the eradication of the disease is possible in these conditions using the ELISA that is a test more sensitive than the immunodiffusion.
\end{abstract}

Keywords: bovine enzootic leukosis; indirect ELISA; agar-gel immunodiffusion; eradication; maternal antibodies.

\title{
Agradecimentos
}

A Joint FAO/IAEA, Agriculture and Biotechnology Laboratory, Agency Laboratories Division, Seiberdorf, Austria, pelo fornecimento dos kitse o apoio no estabelecimento do Setor de ELISA do LIDEA, e ao Conselho Nacional de Desenvolvimento Científico e Tecnológico (CNPq), pelo apoio financeiro. 


\section{Referências bibliográficas}

BAUER, T. H., WIEGAND, D., MANZ, D. Verleichende serologische Untersuchungen an Blut- und Milchproben zur Diagnostic der enzootischen Leukose des Rindes mittels des AGIDT und des ELISA. Dtsch. Tierärztl. Wschr., n. 91, p. 313-318, 1984.

BAUSE, I., MAAS-INDERWIESEN, F., SCHMIDT, E. W. Results of an epidemiological survey of enzootic bovine leukosis in the northern part of Lower Saxony and a preliminary communication of an examination into the relationship between BLV-antibody development and calving. Ann. Vet. Res., n. 9, p. 765-769, 1978.

BAUSE, I., SCHMIDT F.W. Zur Persistenz precipitierender Antikörper in Blutseren leukoseinfizierter Rinder unter besonderer Berücksichtigung des Kalbezeitpunktes. Tierärztl. Umschau, n. 35, p. 642-649, 1980.

BEHRENS, F., ZIEGELMAIER, R., TOTH, T., KEYSERLINGK, M, FORSCHNER, E. Rinderleukose - Diagnostic: ELISA - ein neues Verfahren. Berl. Münch. Tierärztl. Wschr., n. 92, p. 429-432, 1979.

BEX, F., BRUCK, C., MAMMERICKX, M., PORTETELLE, D., GHYSDAEL, J., CLEUTER, Y. Humoral antibody response to bovine leukemia virus infection in cattle and sheep. Cancer Res., n. 79, p. 1188-1190, 1979.

BIRGEL JUNIOR, E. H., D'ANGELINO, J., BENESI, F. J., BIRGEL, E. H. Prevalência da infecção pelo vírus da leucose dos bovinos, em animais da raça Jersey, criados no Estado de São Paulo. Pesq. Vet. Bras., n. 15, p. 93-99, 1995.

BURNY, A., BRUCK, C., CHAUTRENNE, H., CLEUTER, Y., DEKEGEL, D., GHYSDAEL J., KETTMANN, R., LECLERCQ, M., LEUNEN, J., MAMMERICKX, M., PORTELLE, D. Bovine leukemia virus: molecular biology and epidemiology. In: Viral Oncology (Ed. Klein G), Raven Press, New York, p. 231289, 1980.

BURNY, A., BRUCK, C., CLEUTER, Y.; CONEZD., DESCHAMPS, J., GREGORY, D. Bovine leukemia virus and enzootic bovine leukosis. Ondestepovot J. Vet. Res., n. 52, p. 133-144, 1985.

BURRIDGE, M. J., THURMOND, M. C., MILLER, J. M., SCHMERR, M. J., VAN Der MAATEN, M. J. Fall in antibody titer to bovine leukemia virus in the periparturient period. Can J. Comp. Med., n. 46, p. 270-271, 1982.

COCKERELL G.L., ROVNAK J. The correlation between the direct and indirect detection of bovine leukemia virus infection in cattle. Leuk. Res., n.12, p. 465-469,1988.

CORDEIRO J.L.F., DESCHAMPS F.C., MARTINS E., MARTINS V.M.V. Identificação e controle da Leucose Enzoótica Bovina (LEB) em um rebanho leiteiro. Pesq. Agrop. Bras., n. 29, p. 1287-1292, 1994.

FERRER J.F., PIPER C.E., ABT D.A., MARSHAKP.R., BHATT D. Natural mode of transmission of the bovine C-type leukemia virus. Bibl. Haematol., n. 43, p. 235-237, 1976.
ISLAS A., MONTES G., LÓPEZJ., ROJAS K. Leukosis enzoótica bovina: induccion experimental de la infeccion con dos fuentes del virus. Arc. Med. Vet., n. 27, p. 117-120, 1995.

KLINTEVALLK, BERG A., SVEDLUND G., BALLAGI-PORDÁNY A., BELÁK S. Differentiation between enzootic and sporadic bovine leukosis by use of serological and virological methods. Vet. Rec., n. 133, p. 272, 1993.

MANZ D., WIEGAND D., BEHRENS F., ZIEGELMAIER R. Vergleichende serologische Untersuchungen an Blut und Milch zur Diagnostic der enzootischen Leukose der Rinder. Zbl. Vet. Med. B., p. 280-290, 1981.

MÉSZÁROS, J., ANTAL, T., POLNER, A., SZABÓ, I., SZENTMIKLÓSSY, C. S., TEKES, L. [Experiences of the eradication of bovine leucosis in Hungary.] Magy. Áo. Lapja, n. 41, p. 277-285, 1986.

MILLER, J. M., MILLER, L. D., OLSON, C., GILLETTE, K. G. Virus like particles in phytohemagglutinin-stimulated lymphocyte cultures with reference to bovine lymphosarcoma. J. Natl Cancer Inst., n. 43, p. 1297-1305, 1969.

MILLER, J. M., SCHMERR, J. F., VAN Der MAATEN, M. J. Comparison of four serologic tests for the detection of antibodies to bovine leukemia virus. Am. J. Vet. Res., n. 42, p. 5-8, 1981.

MODENA, C. M., LEITE, R. C., MOREIRA, E. C. Evolução sorológica da Leucose Enzoótica Bovina em bezerros. Arq. Fac. Vet. Univ. Fed. RS., n. 12, p. 93-97, 1984.

OLIVEIRA, A. R., IKUNO, A. A., MUELLER, S. B. K., BARETTO, K. S. F., SAAD, V. M. Leucose bovina: ocorrência da anticorpos em bovinos de várias faixas etárias. $R$. Bras. Vet. Med., n. 16, p. 46-50, 1994.

PIPER, C. E., FERRER, J. F., ABT DA, MARSHAK, R. R. Postnatal and prenatal transmission of the bovine leukemia virus under natural conditions. J. Natl Cancer Inst., n. 62, p. 165168, 1979.

ROMERO, C. H., CARVALHO, E. M. R. Transmission of bovine leukemia virus through milk ingestion. Rev. Microbiol., $\mathrm{n}$. 14, p. 109-114, 1983.

TEKES, L. [Possibility for the eradication of bovine leucosis on farms where the infected and noninfected animals were housed in a common interior area]. Magy. Áo. Lapja, n. 44, p. 69-72, 1989.

Influence of management technology and parturition on antibody levels in cows with bovine leucosis. Acta Vet. Hung., n. 42, p. 57-67, 1994.

MÁTÉ Zs., RUSZKA Gy. [A serological survey on the distribution of leucosis in different cattle breeds in Hungary ]. Magy. Áo. Lapja, n. 39, p. 202-204, 1984.

VAN Der MAATEN, M.J., MILLER, J. M. Virus Infections of Ruminants. Dinter Z. and Morein B. (ed). Elsevier Science Publishers, Amsterdam, 1990. 